\title{
Medir a discriminação
}

Devah Pager Tradução de Norberto Guarinello e João Henrique Costa

A discriminação é, há muito tempo, um tema fascinante e frustrante para os cientistas sociais. Fascinante por ser um mecanismo poderoso, subjacente a muitos padrões históricos e contemporâneos de desigual dade; frustrante por ser evasivo e difícil de medir. M ais de um século de interesse das ciências sociais na questão da discriminação produziu inúmeras técnicas destinadas a isolar e identificar sua presença ea documentar seus efeitos. Talvez mais do que qualquer outro tema nas principais linhas de pesquisa sobre a desigual dade, aquelevoltado para a discriminação tem se preocupado tanto com métodos como com conteúdo. N este artigo, descrevo os métodos dominantes que têm sido empregados para estudar a discriminação, incluindo estudos de percepção, sondagem de atitudes, análises estatísticas, experimentos de laboratório e experimentos de campo. Boa parte da discussão centra-se na discriminação racial, na medida em que essa aplicação específica concentrou a atenção da literatura de pesquisa. Um conjunto muito semel hante de prioridades e preocupações aplica-se, igual mente, a uma vasta gama de temas, incluindo o estudo do estigma criminal e de outras formas importantes de diferenciação social.

Todas as abordagens discutidas aqui têm suas próprias vantagens e limitações. Cada método debate-se entre as alternativas opostas da validade interna (a certeza de que o que estamos medindo érealmentediscriminação) e da validade externa (a de que nossas medições são relevantes em relação aos 
contextos da vida real). Por exemplo: estudos baseados em entrevistas, ou em análises estatísticas degrandeescala, representam freqüentemente bem a população em geral, mas deixam uma margem de incerteza quanto à precisão de suas medidas sobre discriminação. Por outro lado, métodos experimentais propiciam meios para isolar as conseqüências da discriminação, embora seu formato de pesquisa seja, muitas vezes, demasiadamentedistantedos contextos sociais reais nos quais ela acontece. Experimentos decampo oferecem uma solução queaproxima essas prioridades opostas ao adotar formatos experimentais no contexto de situações do mundo real. $N$ a discussão que se segue, apresento uma breve síntese das diferentes abordagens, examinando as vantagens e limitações de cada uma. No exame desses métodos a questão principal que procuramos responder é: como sabemos realmente quando e ondea discriminação está em jogo?

\section{"Reconheço-a quando a vejo" : percepções da discriminação em contextos cotidianos}

Para alguns, a discriminação é tão fácil de detectar quanto um desastre ferroviário à luz do dia. Ela é percebida por meio de pistas sutis no modo como os outros são tratados ao nosso redor ou na maneira como nós mesmos somos tratados. A conversa áspera com 0 atendente da loja, o segurança que aguça sua atenção, o taxista que não pára. Seja pela idade, gênero, raça, deficiência, orientação sexual, seja por qualquer outra identidade estigmatizada, a maioria consegue pensar em, no mínimo, um caso no qual nós ou alguém próximo foi tratado de modo injusto por causa de uma única diferença de condição. $N$ esses casos, não é necessária a presença de um cientista social para definir o caso como discriminação.

O s cientistas sociais tiraram proveito das percepções e interpretações dos indivíduos a respeito de sua experiência vivida perguntando às pessoas sobre seus próprios contatos com a discriminação. Estudos documentaram percepções de discriminação em mulheres, pessoas mentalmente doentes, homossexuais masculinos e femininos, e obesos, entre outros (cf. Corrigan et al., 2003; C arr e Friedman, 2005). N ão é surpreendente que a maior parte das pesquisas sobre percepções de discriminação refira-se a minorias raciais (cf. Smith, 2001; Schuman et al., 2001). N umerosas sondagens perguntaram a afro-americanos e a outras minorias raciais sobre suas experiências com discriminação no lugar de trabalho, na busca por moradia ou em outros contextos sociais cotidianos. U ma das conclusões 
mais alarmantes desse tipo de pesquisa é a freqüência com a qual a discriminação é relatada. Por exemplo, uma recente pesquisa geral $\mathrm{G}$ allup atestou que cerca de metade dos entrevistados negros afirmava ter experimentado discriminação em uma de cada cinco situações comuns no último mês ${ }^{1}$. Além disso, a freqüência dos relatos de discriminação não diminui na mesma medida em que os negros sobem na hierarquia social; com efeito, negros da classe média percebem a discriminação na mesma proporção que negros da classe trabalhadora, senão mais (cf. Feagin e Sykes, 1994; Kessler et al., 1990).

Q ue podemos afirmar dessas descobertas? U ma conclusão importante é que os afro-americanos - e outros grupos estigmatizados - sentem a discriminação como al go quepermeia suas vidas. Essaé, por si só, uma descoberta importante. As pesquisas mostram que os que percebem um elevado grau de discriminação são mais propensos a sofrer de depressão, ansiedade e outros problemas de saúde (cf. Kessler et al., 1990). 0 queignoramos, a partir dessalinha de pesquisa, éo quanto essas tendências representam apenas percepções, confrontadas com uma descrição acurada da realidade. Se alguns casos de discriminação são indubitáveis, muitos deixam espaço à interpretação equivocada ou à distorção. Um balconista rude pode estar num dia ruim; um segurança pode estar atento a qualquer passante; 0 taxista pode, simplesmente, não ter visto o pedestre acenando para ele. 0 que éuma evidência flagrante de discriminação, a partir de um ponto de vista, pode ser apenas um mal-entendido a partir de outro.

0 problema de confiar nas percepções em nossa medição da discriminação não reside apenas no fato de que al guns casos podem ser amplificados para além de suas proporções reais. 0 oposto pode ser também um problema - atos de discriminação são, com freqüência, imperceptíveis para a vítima. Em virtude de normas sociais ou de sanções legais, as formas contemporâneas de discriminação raramente são abertas, o que torna inumeráveis casos de ação discriminatória invisíveis para as próprias pessoas que foram alvos dela². Embora seja muito importante para a experiência vivida e concreta dos indivíduos (validade externa), o emprego de percepções só pode oferecer um retrato incompleto da existência da discriminação (validade interna). Para se aproximar da fonte da ação discriminatória, os pesquisadores voltaram sua atenção para os próprios discriminadores em potencial.
1. Essas situações incluem: fazer compras, interação no trabalho, jantar fora, envolvimento com a polícia, uso do transporte público.

2.D a mesma maneira, pesquisas sugerem que indivíduos podem subestimar e/ou suprimir a ocorrência de discriminação em suas vidas, ainda que tenham consciência de altosíndices de discriminação contra seu grupo (cf. Crosby, 1984; Taylor et al., 1990). 
3. Referência às leissegregacionistas que vigoraram entre 1876 e 1967 nos estados do Sul dos Estados Unidos(Jim Crow Laws). Umadesuas principais determinações foi o estabelecimento delugares separados para negros e brancos em locais públicos, como trens e ônibus e escolas (N.T.).

4. Tabulações contemporâneasdeatitudes, no entanto, mostram de fato um viés racial intenso. Smith (1991) relata resultados de uma série de escalas em que se pedia aos entrevistados para classificar vá riosgrupos raciais/étnicos de acordo com características opostas (violento/não-violento, trabalhador/preguiçoso etc.), nos quais os ne gros são classificados de modo mais negativo do que brancos e outros gruposétnicos. M astais tabulações não formam uma série temporal, 0 queimpossibilitadeterminar em que medida essas classificações podem ter se alterado ao longo do tempo.

5.Pesquisadores integraram formalmente opiniões sobre política e políticas públicas
"Não sou racista, mas..." : auto-retratos e pesquisa de atitudes sobre discriminação

Em vez de basear-se na percepção das vítimas, outra linha de pesquisa sociológica centra-se nas atitudes gerais e nas ações de grupos dominantes para obter pistas sobre quando e como considerações raciais entram em jogo. A linha de trabalho mais desenvolvida nessa área é a longa tradição de sondagens sobre atitudes raciais. Já há décadas perguntas semelhantes têm sido levantadas em pesquisas de cobertura nacional como Gallup e G eneral Social Survey, entre outras, aferindo as opiniões de norte-americanos brancos sobre temas como relações raciais e desigual dade racial. Pelo fato de as mesmas perguntas terem sido feitas ao longo de muitos anos, podemos mapear mudanças nas atitudes raciais expressas pel os norte-americanos ao longo do tempo. E, na verdade, de acordo com esses itens, houve grandes mudanças nas relações raciais desde a época de Jim Crow ${ }^{3}$. $N$ as décadas de 1940 e 1950, por exemplo, menos da metade dos brancos nas sondagens achava que estudantes brancos deviam ir à escola com estudantes negros, ou que negros e brancos que se candidatavam a um emprego deveriam ter oportunidades iguais de obtêlo. Na década de 1990, ao contrário, mais de $90 \%$ dos entrevistados brancos da sondagem apoiavam o princípio de que estudantes brancos e negros, assim como os candidatos a um emprego, deveriam ser tratados de maneira igual por escolas e por empregadores (cf. Schuman et al., 2001). Tais mudanças de atitude ao longo do tempo efetivamente sugerem um declínio substancial no preconceito e implicam o fato de que formas abertas de discriminação e de hostilidade racial não são mais aceitáveis para a maioria do público norteamericano ${ }^{4}$.

Alguns críticos, no entanto, põem em dúvida o fato de que tais tendências possam ser interpretadas como indicadores de uma mudança significativa nas atitudes raciais subjacentes. D estacando a falta de apoio a programas que visam a concretizar os princípios largamente apoiados de igual dade como programas de transporte escolar para obter integração racial nas escolas ou de ação afirmativa para apoiar a diversidade na educação superior ou nos postos de trabalho -, esses pesquisadores questionam o endosso aos princípios de igualdade como sendo superficial (cf. Kinder e Sears, 1981; B obo et al., 1997)5. Se não se vinculam ao apoio a mudanças sociais significativas, o que exatamente essas atitudes nos dizem sobre o estado das relações raciaishoje? 
U ma das principais críticas à pesquisa de atitudes diz respeito ao fato de ela ser vulnerável ao viés do que é socialmente desejável, ou seja, à pressão sobre os entrevistados por respostas "politicamente corretas", mesmo que isso implique distorcer ou desmentir suas crenças verdadeiras. Ao mapear tendências de atitudes raciais ao longo do tempo, é difícil separar as mudanças nas crenças dos entrevistados das pressões crescentes no sentido de apresentar respostas socialmente apropriadas (não discriminatórias). Esseé um problema que tem, sem dúvida, atraído grande atenção dos cientistas sociais. Paralelamente às questões tradicionais sobre opinião pública, os pesquisadores desenvolveram algumas abordagens inovadoras para medir atitudes empregando técnicas que são consideradas menos vulneráveis à distorção por pressão social. D uas delas, que se destacam como particularmente promissoras, incluem formatos de sondagem experimental e procedimentos de entrevista em profundidade.

Técnicas de sondagem experimental foram desenvolvidas para estudar tópicos delicados, tais como as atitudes sobre raça, oferecendo a oportunidade de aferir diferenças nas avaliações de distintosgrupossem requerer nenhuma comparação direta entre eles. Em vez disso, grupos al eatórios de entrevistados são expostos a uma entre diferentes variantes de pergunta do questionário para atribuir respostas a um grupo ou condição particulares ${ }^{6}$. U m estudo deH oward Schuman eL awrenceBobo (1988), por exemplo, empregou um formato deamostragem dividida (split-ballot), no qual era perguntado paraa metadedaamostrase "sesentiriam muito, um pouco ou nadaincomodados" se uma família de norte-americanos de origem japonesa se mudasse para a vizinhança, enquanto à outra metade apresentava-se a mesma questão com relação a uma família negra. Esse estudo identificou de modo significativo mais reações negativas no caso da família negra: se cada entrevistado tivesse que responder sobre uma família negra ou japonesa na mesma pesquisa, poderia ter direcionado suas respostas para uma aval iação semelhante dos dois grupos, compatível com as normas detratamento igual. Por meio decomparações estatísticas entre os dois grupos, estudos de amostragem dividida são considerados capazes de produzir estimativas válidas para a população em geral quanto à importância da raça para a questão em pauta, ao mesmo tempo em quereduzem a influência do viés do socialmentedesejável derivado de comparações raciais diretas ${ }^{7}$. Formatos de pesquisa experimental apresentam claras vantagensna mensuração de itens sensíveis, eseus resultados reve laram de modo concreto uma ocorrência maior de preconceito em relação aosformatos tradicionais de sondagem. nos itens que medem atitudes raciais. A Escala Moderna de Racismo, por exemplo, inclui conjuntos de itens destinados a medir formas tradicionais de preconceito racial, e outras mais sutis e "modernas" (cf. M cConahay, 1986), que incluem a crença de que os negros foram mais favorecidos economicamente do que merecem, de que eles são muito exigentes e de que a discriminação não é mais um problema (cf. $\mathrm{N}$ ational Research Council, 2004, p. 176).

6. Para uma visão geral, ver Sniderman e Grob (1996).

7.0 s resultados dessa sondagem, na verdade, indicam uma oposição bastante maior a uma família negra que se mude para a vizinhança $(19,6 \%)$ do que a uma de nipo-americanos $(10,4 \%)$. U maversão posterior do item sondado, com a frase "com a mesma renda e escolaridade", não reduziu as disparidades (18,6\% versus $2,7 \%$ afirmaram se importar com, respectivamente, uma família de negros ou denipo-americanos 
com a mesma escolaridadeerenda). Vertambém Schuman (1995).

8. Ver Pager eQ uillian (2005).
O s problemas relativos ao viés do que é socialmente desejável, contudo, não estão ausentes por completo no caso de formatos de sondagem experimental. Ainda que não sejam pedidas comparações raciais diretas em questionários específicos, os entrevistados podem dar-se plenamente conta - de modo consciente ou não - de que a questão racial está em jogo ${ }^{8}$. Q uando perguntado sobre um vizinho negro, por exemplo, um entrevistado branco pode aumentar artificialmente sua taxa de aprovação, mesmo sem uma comparação direta com outro vizinho branco ou asiático. Raça é um tema tão carregado nos Estados U nidos que indivíduos podem reagir - ou reagir à sua reação - à sua mais simples menção. T écnicas de sondagem experimental não são imunes a ameaças à sua validade interna, ainda que possam oferecer melhoras substantivas com relação à pesquisa tradicional por sondagem.

U ma preocupação talvez mais importante com relação ao emprego de itens diagnósticos nas sondagens sobre discriminação seja a incerteza em relação a como atitudes auto-assumidas correspondem a al gum padrão significativo dentre os comportamentos esperados. Embora se admita correntemente que há uma estreita ligação entre atitudes e comportamentos, a pesquisa concreta - em especial aquela voltada para temas como preconceito racial e discriminação - tem encontrado, de modo surpreendente, muito pouca correspondência entre ambos (cf. LaPierre, 1934; Kutner et al., 1952; Saenger e Gilbert, 1950; Pager e Q uillian, 2005). Essa pesquisa nos põe em alerta para o fato de que é difícil antecipar como qualquer indivíduo, inclusive ele próprio, reagirá a uma situação na qual se viu envolvido previamente apenas em termos hipotéticos. Formatos sofisticados de sondagem podem detectar com sucesso um viés racial, mas as implicações desse fato diante de manifestações concretas de discriminação não são claramente visíveis. A questão da validade externa de formatos de sondagem - ao menos em sua função de prever comportamentos - permanece assim em aberto.

Técnicas de sondagens experimentais visam a aumentar a precisão das respostas, apresentando estímulos-chave por meio de protocolos altamente controlados; tais técnicas conferem à pesquisa por sondagem uma maior complexidade e precisão. M ovendo-se em direções opostas, entrevistas realizadas em contextos menos formais com níveis de estruturação mais baixos também se revelaram efetivas na aferição das opiniões dos entrevistados sobre tópicos sensíveis. Entrevistas em profundidade, personalizadas, mostraram-se particularmente eficazes para provocar discussões sinceras sobre 
questões delicadas relativas à contratação de empregados (cf. Kirshenman e N eckerman, 1991; W ilson, 1996; M oss e Tilly, 1996; N ewman, 1999). $N$ esses contextos, os pesquisadores normalmente propiciam um local de encontro confortável e conveniente para o entrevistado, e o questionário segue normalmente um formato semi-estruturado que permite aos entre vistados enfatizar as questões que lhes parecem mais importantes. As entrevistas duram com freqüência até duas horas por pessoa e são, por vezes, conduzidas em múltiplas sessões. Estima-se que a possibilidade de construir um relacionamento no contexto da entrevista personal izada reduza as pressões do que é socialmente desejável, dando maior confiabilidade aos entrevistados para expressar crenças contrárias às normas. D a mesma forma, essas entrevistas em aberto possibilitam a discussão quanto à complexidade e, por vezes, às inconsistências das opiniões dos entrevistados sobre grupos diferentes, indo além das afi rmações mais genéricas manifestadas pelos indicadores de sondagens. Com efeito, pesquisadores que empregam essa abordagem encontram normalmente um maior número de entrevistados dispostos a expressar níveis muito mais elevados de preconceito e endossar estereótipos raciais mais abertamente do que quando se empregam as técnicas de sondagem. Joleen K irschenman eK athryn N eckerman, por exemplo, descrevem como empregadores reconhecem de modo absolutamente explícito sua recusa em admitir jovens negros e moradores do centro da cidade em sua busca por trabalhadores. Ao atribuir a esse grupo características como "preguiçoso" ou "não confiável", os empregadores incluídos nesse estudo não escondem o fato de que parecem adotar práticas claramente discriminatórias para a contratação de empregados (Kirschenman e N eckerman, 1991, p. 213) ${ }^{9}$.

Tais estudos em profundidade têm sido valiosos por oferecer relatos circunstanciados do que se passa na mente dos empregadores - ao menos conscientemente - quando avaliam membros de grupos distintos. A principal limitação desse tipo de pesquisa é a confiabilidade na propensão dos empregadores a expressar suas verdadei ras atitudes e crenças. Tendemos a acreditar nesses resultados porque produzem relatos de preconceito acima do esperado. Contudo, se essa é nossa única medida de val idação, encontramo-nos diante de um raciocínio circular, no qual a avaliação do método depende do conteúdo de seus resultados. Se os empregadores entrevistados revelam um viés racial, a entrevista deve ser precisa; mas o que acontece se revelam pouco viés - poderíamos pensar que, nesse caso, os empregadores dizem a verdad $\mathrm{e}^{10}$ ?
9.Ver também W ilson (1996); Moss e Tilly (1996).

10. 0 utra limitação das entrevistas em profundidade é a necessidade de investimentos extraordináriosem tempo e recursos para completálas, o queredundaem amostragens relativamente pequenas. Embora al guns projetos tenham atingido amostragens substancialmente maiores (cf. Wilson, 1996, p. 179; Moss e Tilly, 1996, p. 174), a escala desses estudos é tímida perante os númerosobtidospor técnicas de sondagem mais tradicionais. 
"Qualquer coisa, menos a pia da cozinha" : análises estatísticas de bancos de dados de grande escala

Provavelmente a abordagem mais comum no estudo da discriminação seja a que investiga desigualdades nos resultados sociais entre grupos. Em vez de focal izar nas atitudes ou percepções dos agentes possivelmente envolvidos em atos de discriminação, essa abordagem tem em vista as conseqüências possíveis da discriminação na distribuição desigual do emprego ou de outro recurso social e econômico. Empregando bancos de dados de grande escala a partir do recenseamento ou de outra amostragem qualquer da população, os pesquisadores podem empregar técnicas estatísticas para determinar diferenças nos padrões de emprego ou renda por raça de indivíduos com níveis equivalentes de escolaridade, experiência de trabalho ou qualquer outra característica relacionada. U ma análise realizada por $C$ ancio et al. (1996), por exemplo, mostra que homens negros recebem aproximadamente $74 \%$ de cada dólar obtido por homens brancos semelhantes, feitos os controles sobre educação, experiência no serviço, tempo de emprego, área de residência, statuscivil e dos pais e origem familiar. Essa pesquisa implica que a diferença de $26 \%$, não explicável por variáveis significativas do mercado de trabalho medidas por essa pesquisa, é provavelmente resultado de discriminação racial. Se negros (ou ex-condenados) com as mesmas qualificações percebem menos que brancos (ou não-condenados) igualmente qualificados, que outra razão haveria? Como os críticos responderam rapidamente, um grande número de explicações alternativas poderia ser proposto. Diferenças na habilidade verbal, no trato interpessoal, na motivação, nos hábitos de trabalho poderiam explicar al gumas das disparidades observadas na obtenção de emprego; diferenças no acesso ao sistema de transporte, às redes sociais e a outras fontes de informação poderiam, igualmente, explicar parte da diferença (cf. M oss eT illy, 1996; Farkas, 2003; Fernandez eSu, 2004). É difícil medir diretamente a influência de muitas dessas possibilidades (não há medições nas sondagens sobre, por exemplo, pontualidade), mas seria da mesma maneira impossível descartá-las por completo. É verdade que a discriminação éuma explicação possível para parte ou toda a desigualdademe dida entre os grupos, mas muitos outros fatores também o são. 0 calcanharde-aquiles da pesquisa por sondagem é, na verdade, sua incapacidade em dar efetivamente conta das muitas fontes possíveis de distorção (ou causas não medidas), o que compromete sua capacidade de estabelecer vínculos causais precisos. Se a força dessa linha de pesquisa reside em seu grande poder esta- 
tístico para detectar diferenças entre grupos (os dados do censo, por exemplo, abrangem mais de 1 milhão de entrevistados!) no contexto do funcionamento real do mercado de trabalho (por exemplo, emprego e salários), sua limitação reside em sua capacidade para explicá-las de modo conclusivo.

Experimentos de laboratório sobre discriminação

Experimentos sociopsicológicos sobre estereótipos raciais e discriminação têm seu ponto forte precisamente nas áreas em que as análises estatísticas tropeçam. Experimentos de laboratório conduzidos em ambientes altamente controlados oferecem pistas sobre os mecanismos pelos quais vieses raciais são provocados, processados e expressos. O s experimentos começam geralmente sob condições claramente definidas como "tratamento" e "controle", às quais indivíduos são al eatoriamente designados ${ }^{11}$. Todas as demais influências ambientais são cuidadosamente controladas. U ma variável resultante específica é então registrada para testar diferenças entre os grupos. 0 s indivíduos, com freqüência, desconhecem o objetivo do experimento, para assegurar uma reação ingênua ou "natural" à condição deste.

Em um estudo recente, por exemplo, indivíduos foram levados a crer que participariam de uma discussão com dois outros estudantes, seja sobre um tópico relacionado a raça (por exemplo, definir um perfil racial), seja sobre um tópico neutro em termos raciais (por exemplo, relacionamentos românticos). M etadedosindivíduosfoi levadaa crer que seusinterlocutores seriam negros (grupo detratamento); metade acreditava que os interlocutores seriam brancos (grupo de controle). Enquanto os interlocutores fictícios eram esperados, requisitava-se ao indivíduo que arranjasse as três cadeiras dispostas em linha junto a um canto da sala, "de modo que vocês três possam ter uma conversa confortável". Sem quea pessoa soubesse, a disposição das cadeiras era o verdadeiro foco do experimento. 0 s pesquisadores mediram a distância que separava as cadeiras dispostas por cada indivíduo (variável resultante), deacordo com a raça dos outros estudantes esperados ecom o tema proposto para discussão. O s achados indicam que a raça tem um efeito significativo na distância entre as cadeiras - mas apenas quando 0 indivíduo tem a expectativa de discutir temas controversos, tais como perfil racial (cf. G off, 2005). Esses resultados sugerem que a ansiedade com relação à interação entre raças não éuniforme. Ao contrário, al gumasinterações (ou interações antecipadas) despertam altos níveis de ansi edade e atos cor-
11. A designação aleatória auxilia a eliminar a influência que as características pessoais de um dado sujeito possam ter sobre osresultados, na medida em que rompe o vínculo entre as características do sujeito e sua escolha para submeter-se às condições de tratamento. 
respondentes de distanciamento social. Formatos de pesquisa criativos como esse permitem aos pesquisadores investigar os meios sutis pel os quais o comportamento é influenciado por considerações raciais, mesmo quando tais influências permanecem completamente inconscientes para o próprio indivíduo (masculino ou feminino).

Experimentos laboratoriais têm sido extremamente úteis na identificação dos mecanismos pelos quais os estereóti pos raciais exercem sua influência. 0 exemplo anterior atesta a interferência da raça em comportamentos sutis; outros demonstraram o impacto de estereótipos raciais na memória seletiva ou distorcida para informações compatíveis com o estereótipo (cf. Bodenhausen, 1988; Sagar e Schofield, 1980). Compreender os processos cognitivos e interpretativos que ocorrem quando uma informação racial está sendo processada ajuda a entender como os estereótipos exercem sua influência e como surge a discriminação.

A força dos experimentos de laboratório reside, claramente, na identificação de efeitos causais; podemos isolar a influência da raça sobre o comportamento sem a interferência de outros fatores que poderiam levar à confusão. A principal limitação dos experimentos, contudo, diz respeito à sua capacidade de generalização para contextos do mundo real. Tendo em vista o fato de que esses estudos são normalmente conduzidos em contextos laboratoriais sob condições relativamente forçadas, é difícil saber em que medida os achados se aplicariam em contextos sociais mais cotidianos. D a mesma maneira, sua capacidade de general ização éainda mais limitada pelo fato de a maioria dos experimentos utilizar como amostragem alunos de graduação em psicologia. Como podemos assegurar que o processamento do fator raça éo mesmo entre estudantes de psicologia de 19 anos de idade, entre empregadores na faixa dos 50 anos ou entre a população em geral? $\mathrm{Na}$ verdade, algumas pesquisas sugerem que os resultados da investigação variam simplesmente mudando-se a faculdade do universo da amostra; que dizer então de outras variáveis demográficas fundamentais (cf. M arwell e Ames, 1981)? Se al gumas das mais fortes evidências de relação causal são oferecidas por experimentos de laboratório, é muito difícil determinar em que medida seus resultados aplicam-se a decisões concretas tomadas nos contextos sociais - por exemplo, empregar, alugar, mudar-se -, mais importantes para a compreensão das formas de discriminação que produzem disparidades sociais significativas. Em busca de um maior realismo da investigação, os pesquisadores transferiram os experimentos do laboratório para o campo. 
Evidência clara e convincente; experimentos de campo sobre discriminação

Experimentosdecampo combinam métodos experimentaiscom pesquisa propriamente decampo, afrouxando certos controles sobreas influências ambientais a fim de melhor simular interações do mundo real. Ao mesmo tempo em que mantém certas características-chave do método experimental, como amostragens duplas edesignação al eatória, importantes para asinferências sobre causalidade, essa abordagem baseia-se em contextos reais (por exemplo, procura real de emprego, mercado imobiliário, transações com o consumidor) para a aplicação de suas técnicas de mensuração. Por exemplo, em vez de pedir a estudantes universitários que classifiquem candidatoshipotéticosaum emprego num testedelaboratório, um experimento de campo apresentaria dois candidatos igualmente qualificadosa empregadores reaisno contexto real deprocura por emprego.

Experimentos de campo concebidos especificamente para medir discriminação são geralmente designados como estudos de auditagem. 0 s estudos pioneiros da metodologia de auditagem surgiram nos anos de 1970 com uma série de auditorias conduzidas pelo $\mathrm{D}$ epartamento de $\mathrm{H}$ abitação eD esenvolvimento U rbano para aferir a discriminação racial nos mercados imobiliários (cf. Yinger, 1995; W ienk et al., 1979; H akken, 1979). D esde então, a abordagem tem sido adotada por diferentes órgãos estatais, organizações não-governamentais e pesquisadores universitários para medir a discriminação segundo raça, idade, gênero e outras qualificações protegidas. A metodologia de auditagem tem sido aplicada em numerosos contextos, incluindo hipotecas, mercado imobiliário demoradias, negociações para compra de veículos e chamadas de táxis ${ }^{12}$. No caso de discriminação no emprego, doistipos principais deestudos deauditagem oferecem abordagensúteis: os testes por correspondência e as auditagens em pessoa.

Testes por correspondência: A abordagem dos testes por correspondência, assim denominada por simular a comunicação (correspondência) entre candidatos ao emprego e empregadores, baseia-se em currículos sumários fictícios emparelhados (matched), submetidos por correio ou fax aos empregadores. N esses estudos, dois ou mais currículos são preparados apresentando os mesmos níveis de escolaridade e experiência. A raça (ou outra característica de grupo) do candidato fictício é sugerida por meio de uma ou mais pistas, com a raça sendo designada de modo aleatório a tipos de currículo sumário distribuídos entre os empregadores (ou seja, o status de minoria é atribuído a um currículo somente para metade dos empregadores; isso visa
12. Ver Turner e Skidmore (1999), Ayres e Siegelman (1995), Ridley et al. (1989), Yinger (1995), M assey e Lundy (2001), Cross et al. (1990), Turner et al. (1991), Bendick et al. (1994) e Neumark (1996). Para uma revisão das experiências com experimentos de campo em contextosinternacionais, ver Riach e Rich (2002). 
13. N ossadiscussão centra-se no caso da discriminação racial, mas esses métodos podem ser facilmenteaplicadosem estudos sobre discriminação de gênero, idade, bairro e muitas outras categorias sociais. a assegurar que qualquer diferença entre os currículos não tenha correlação com os efeitos mensuráveis da raça) ${ }^{13}$. As reações dos empregadores são então medidas geralmente a partir das respostas escritas (remetidas a endereços criados para receber essa correspondência) ou das respostas telefônicas (para cai xas el etrônicas de mensagem) para cada candidato. U m estudo exemplar dessetipo foi realizado recentemente por $M$ arianne Bertrand eSendhil M ullainathan (2004). N ele, os pesquisadores prepararam dois grupos de currículos emparel hados refletindo dois grupos de candidatos com dois níveis de especialização. Empregando nomes racial mente marcados para assinalar essa característica nos candi datos, os pesquisadores enviaram por correio currículossumáriosa cerca de 1.300 empregadores em C hicago eBoston. O s resultados indicam que os nomes que "soavam" como de brancos tinham uma possibilidade $50 \%$ maior de obter respostas positivas dos empregadores do que outros candidatos, igualmente qualificados, com nomes "negros". Além disso, candidatos com nomes brancos conseguiam vantagens significativas com relação a qualificações adicionais para o emprego, algo que aqueles com nomes negros não obtinham. 0 fosso racial entre os candidatos a emprego era, dessa forma, maior entre os pares de candidatos mais qualificados que entre aqueles com menor qualificação.

A vantagem da abordagem do teste por correspondência é não requerer candidatos reais a emprego (apenas candidatos fictícios, de papel), o que é desejável tanto por razões metodológicas como práticas. Em termos metodológicos, o uso de pessoas fictícias permite aos pesquisadores criar duplas de candidatos cuidadosamenteemparel hadas sem a necessidade de levar em conta as complexidades de indivíduos reais. 0 pesquisador possui, assim, um controle muito maior sobre o conteúdo preciso das condições de "tratamento" e de "controle". Em termos práticos, o uso de candidatos "de papel" é também desejável em termos da facilidade logística com a qual o processo de candidatura a emprego pode ser efetuado. Em vez de coordenar entrevistas com pessoas reais (possibilitando que os candidatos se percam, ou encontrem o empregador em situações indesejáveis, como quando está almoçando ou recebendo um clienteetc. ), a abordagem do teste por correspondência requer simplesmente quecurrículos resumidossejam enviados em intervalos de tempo específicos. Além disso, o baixo custo da postagem ou das tarifas de fax é irrelevante diante dos custos envolvidos na contratação de pessoas para atua rem como candidatosa emprego.

Embora os testes por correspondência apresentem tantas características atrativas, há também certas limitações nesse formato, o que levou muitos 
pesquisadores a preferir a abordagem por auditagem em pessoa (in-person audit approach).

Problemas na identificação das características chave dos candidatos: tendo em vista que os testes por correspondência baseiam-se apenas em candidaturas "de papel", todas as informações necessárias e relevantes devem ser transmitidas sem as pistas visuais de um contato interpessoal. N os casos de gênero e etnia, pode-se transmitir facilmente a informação necessária empregando nomes que sejam específicos de um gênero ou associados a uma etnia (cf. Riach e Rich, 1991; Lahey, 2005). Em casos de discriminação etária, al guns estudos basearam-se em datas de formatura do Ensino M édio para transmitir a diferença de idade dos candidatos (cf. Bendick et al., 1999; Lahey, 2005). Pesquisadores que desejam estudar as diferenças entre brancos e negros, por outro lado, enfrentam um desafio um pouco maior. 0 estudo de Bertrand e Mullainathan (2004) discutido anteriormente, por exemplo, empregou nomes racialmente distintivos para indicar a raça dos candidatos. N omes como "Jamal" e "Lakisha" indicavam afro-americanos, ao passo que "Brad" e "Emily" estavam associados a brancos. Embora tais nomes possam ser relacionados de modo confiável a seus grupos raciais, al guns críticos argumentam que os nomes mais evidentemente afro-americanos são também associados a uma posição socioeconômica inferior, confundindo a influência diferencial de raça e de classe social. D e fato, a escolaridade da mãe éum elemento que permite prever (de modo negativo) sea criança terá um nome claramente afro-americano ${ }^{14}$. 0 uso de nomes próprios para aferir diferenças entrenegros ebrancos é, dessa maneira, complicado pelo contexto social no qual se situam nomes racialmente distintivos.

O utros estudos de teste por correspondência utilizaram-se da seção "atividades extracurriculares" ou "voluntariado" dos currículos sumários como forma de reforçar o indicador da raça do candidato ${ }^{15}$. Ser membro da liga estudantil do NAACP ( $\mathrm{N}$ ational Association for the Advancement of Colored People), por exemplo, sugeriria fortemente um afro-americano. Ao candidato "branco" emparelhado seria atribuída então uma atividade neutra em termos raciais (por exemplo, a Student D emocratic Alliance), que, sem uma marca racial, é normalmente, ausentes outros fatores, associada a brancos ${ }^{16}$. Independentemente da estratégia adotada, é importante que os currículos passem por um pré-teste cuidadoso antes de ser empregados no campo. N omes, atividades extracurriculares, bairros e escolas podem ter, cada um deles, conotações que não são imediatamente visíveis para o pesquisador. D eterminar diretamente essas conotações/associações é
14.Fryer e Levitt (2004, p. 786) relatam que "nomes 'mais negros' são associados com códigos de endereçamento de renda mais baixa, níveis menores de escolaridade dos pais, ausência de seguro privado, e com o fato de a mãe possuir, ela própria, um nome 'mais negro'".

15. Ver Bendick et al. (1994). N ão seria desejável, no entanto, empregar apenas atividades extracurriculares paraindicar a raça. Essa pista sutil poderia escapar a muitos empregadoresno processo de seleção.

16. $N$ a medida em que candidatos que apresentem atividades extracurriculares "racialmenteneutras" não serão considerados brancos em $100 \%$ dos casos, os resultados obtidos serão mais conservadores. 
17. Para uma abordagem intermediária empregando contato telefônico (usando a voz para indicar raça, classe e gênero), ver M assey e Lundy (2001). um primeiro passo importante no desenvolvimento dos materiais necessários para uma aferição efetiva da discriminação.

Amostragem limitada deempregos: outra limitação importantedo método do teste por correspondência diz respeito aos tipos de emprego passíveis de serem testados. 0 procedimento para candidatura usado nos testes por correspondência - envio decurrículosresumidos- éreservado em geral ao estudo de ocupações administrativas, secretariais ou outras posições "de colarinho branco". A grandemaioria dosprimeirosempregos, ao contrário, requer mais freqüentemente que o candidato se apresente em pessoa. Para empregos como ajudante de garçom, mensagei ro, trabal hos pesados ou caixa, por exemplo, um currículo enviado pelo correio pareceria completamente fora de lugar. Q ualquer estudo do mercado de trabal ho de baixa remuneração requereria, assim, que os candidatos se apresentassem em pessoa. Embora os estudos de auditagem em pessoa também tenham que enfrentar uma gama restrita de ofertas deemprego, candidaturas em pessoa permitem uma amostragem substancial mentemaior do quea obtida com candidaturasfeitas apenas no papel.

Auditagensem pessoa: o uso deauditagensem pessoa, por oposição àquele baseado em currículos enviados pelo correio, representa uma simulação mais elaborada do processo de contratação ${ }^{17}$. Auditagens de emprego em pessoa envolvem o uso de pares combinados de indivíduos (denominados de testadores) que se apresentam como candidatos em buscas reais por emprego. Eles são cuidadosamente emparelhados no tocante a idade, raça, beleza física, estilo de comunicação e quaisquer outras características relevantes para o emprego às quais os empregadores podem atentar ao tomar a decisão de contratar. C omo nos testes por correspondência, currículos são construídos para cada testador, refletindo níveis iguais de escolaridade e de experiência no serviço. Além disso, a apresentação pessoal dos candidatos emparel hados deve ser cuidadosamente controlada. Embora auditagens em pessoa sejam demoradas e requeiram uma supervisão intensa, a abordagem oferece algumas vantagens em relação aos estudos por correspondência. Auditagens em pessoa fornecem um método claro para indicar a raça (por meio da apresentação física dos candidatos); permitem uma ampla gama de tipos de emprego inicial (que freqüentemente exigem a presença do candidato); e oferecem a oportunidade de reunir dados quantitativos e qualitativos, com informações sobre se o candidato obteve ou não o emprego e sobre como foi tratado durante a entrevista. N o restante deste artigo, confronto possíveis críticasao método da auditagem. Eventuais vulnerabilidades 
da metodologia de auditagem merecem uma reflexão cuidadosa, antes de aceitarmos que um formato de experimento de campo possa conferir automaticamente um alto nível de validação interna e externa.

Críticas do método deaudi tagem: Embora a maioria dospesquisadores encare a metodologia de auditagem como a maneira mais eficaz para medir a discriminação, a abordagem tem seus críticos. 0 economista James H eckman éum dos mais ativos questionadores dessemétodo, em especial quando empregado para estudar as influências diferenciais da raça. A crítica fundamental deH eckman (1998, pp. 107-111) centra-sena questão da eficácia do emparelhamento ${ }^{18}$. A validade deum estudo deauditagem baseia-senacapacidade bem-sucedida de apresentar dois candidatos igualmente bem qualificadosao emprego, que difiram apenas em suaraça. Contudo, tendo em vista o vasto número de características que podem influenciar a avaliação de um empregador, é difícil ter certeza de que todas essas dimensões foram efetivamente controladas. $N$ ote-se que na aferição da influência diferencial de um registro criminal, ou de qualquer outra característica que não seja pessoal, taispreocupaçõestêm menos relevância. Como ostestadores podem alternar seu modo de apresentação entre essas condições (por exemplo, com ou sem registro criminal), quaisquer diferenças remanescentes entre o par de testadoresanulam-seefetivamenteao longo do estudo. A raça, pelo contrário, não é algo que possa ser atribuído experimentalmente. D evemos acreditar, portanto, que os pesqui sadores da auditagem foram bem-sucedidos na identificação eno emparelhamento de todas as características relevantes- al go que, segundo $\mathrm{H}$ eckman, abreum vasto espaço para outros vieses. A crítica principal deH eckman centra-senas coisas não observáveis- aquelas características que não são "observáveis para o estudo [pesquisadores] de auditagem, mas são [...] no mínimo um pouco visíveis para o futuro empregador, atuando nas decisões de [... ] contratar". Segundo esseautor, brancosenegros (no âmbito da população em geral) podem diferir na média e/ou na distribuição de características importantes. Por exemplo, considere-se um caso hipotético no qual osbrancos apresentam, em média, uma resposta maisrápida durante as entrevistas do que os negros. 0 u seja, o tempo em segundos entrea questão colocada pelo entrevistador e o começo da respostaé, em média, menor para os brancos que para os negros. ( $N$ a verdade, tempo de resposta éapenas um exemplo em potencial, e deixo muito claro que, pelo que sei, não há nenhuma base empírica nessa afirmação. 0 próprio $\mathrm{H}$ eckman não sugere ne nhum exemplo concreto de coisas não observáveis que fossem potencialmente relevantes a ponto de afetar os resultados das contratações; mas é
18.Em outro texto, $\mathrm{H}$ eckman e Siegelman (1993) identificam cinco riscos potenciais à validade dos resultados de estudos de auditagem: 1) problemas no emparelhamento efetivo; 2 ) uso detestadores "superqualificados"; 3) esquema limitado de amostragem paraaseleção das empresas e empregos a serem auditados; 4) influência diferencial do experimentador; e 5) a ética da pesquisa deauditagem. Para uma discussão útil sobre essas preocupações, ver a série de ensaiospublicadospor Fix e Struyk (1993). Além das críticas expressas por H eckman, os estudos de auditagem são freqüentemente custososedeimplementação difícil, e só podem ser empregados em determinados pontos do processo decisório (por exemplo, decisões sobre contratação, mas não sobre promoção). 
instrutivo levar em contaum caso hipotético concreto parafins de clareza do raciocínio.) Como a diferença na demora em responder seria extremamente sutil, não seria identificável de imediato pel os pesquisadores; mesmo para os empregadores, seria notada apenas num nível subliminar. No entanto, se essa característica produz uma vantagem adicional para o indivíduo com a resposta mais rápida - por ele ser considerado mais esperto ou mais envolvido -, podemos nos enganar com a resposta do empregador com relação à discriminação, já queaval iaçõesnão raciais estão determinando as diferenças entreas respostas.

U m problema relacionado aparece se brancos e negros diferem em características-chave, não na média, mas no nível de dispersão. Para seguirmos com o mesmo exemplo, imagine-se um caso no qual tanto negros como brancos apresentam um tempo médio de resposta de 0,5 segundos, mas os negros mostram maior heterogeneidade ao longo desse espectro do que os brancos. Resultados distintos podem ser observados, dependendo das qualificações mais gerais dos testadores com relação aos requisitos do emprego. Se os testadores são altamente qualificados para os postos de trabal ho aos quais concorrem (o que é a tendência nos estudos de auditagem), a dispersão diferencial de qualquer variável-chave favorecerá o grupo com menor dispersão (porque uma proporção menor de candidatos nesse grupo estará na ponta inferior da curva com relação a um grupo de grande dispersão).

A crítica de H eckman levanta questões importantes e certamente encoraja um exame mais rigoroso da metodologia deauditagem. É útil, em cada caso particular, levar em conta se e como esses questionamentos podem ser enfrentados de modo eficaz. A preocupação de H eckman centra-se na possibilidade de que, se brancos e negros diferirem, de modo geral, em qualquer variável não observada ligada à produtividade, seja na média, seja no espectro de variação, as estimativas obtidas por duplas emparel hadas já trarão um viés no próprio formato. Essa crítica seria certamente válida se os auditores fossem escolhidos al eatoriamente na população e mecanicamente emparel hados por características de fácil mensuração.

É um equívoco, no entanto, considerar que o pesquisador necessariamente tem mais dificuldades que o empregador para identificar características relativas à produtividade. Com efeito, o pesquisador também éum empregador no planejamento ena implementação do estudo de auditagem. 0 trabalho de um testador não é simples, e encontrar uma equipe capaz de levar adiante esse tipo de projeto requer um exame extensivo euma sel eção 
cuidadosa. 0 trabalho exige sólidos conhecimentos de escrita (para os relatórios que sucedem cada auditagem), habilidades comunicativas (para transmitir as informações necessárias em uma entrevista; para provocar uma boaimpressão no empregador), níveis el evados demotivação (quesemantenha dia após dia), confiabilidade (para conduzir e reportar com precisão cada teste), habilidades de localização (para encontrar lugares na cidade) e uma infinidade de outras qualificações. D esse modo, além das características mais evidentes como altura, peso, raça e idade, os pesqui sadores devem procurar por testadores que possam sair-se bem numa situação muito exigente $^{19}$. Como empregador, o pesquisador deve identificar pistas sutis nos candidatos, que indiquem sua habilidade em atuar. Se tais pistas são ou não explícitas, conscientes ou mensuráveis, elas estão tanto presentes na avaliação de um pesquisador de seus candidatos a testadores, como estão nas avaliações dos empregadores ao lidarem com candidatos a um primeiro emprego. C omo os empregadores, os pesqui sadores são afetados por indicadores objetivos e subjetivos/subconscientes das qual idades dos candidatos em seu processo seletivo eno emparel hamento detestadores, de um modo que, em última instância, deve contribuir para uma calibração mais fina entre os pares combinados de testadores ${ }^{20}$.

U ma preocupação de H eckman relacionada a essa diz respeito à possibilidade de o processo de combinação de pares (mesmo quando realizado com sucesso) produzir distorções no processo de contratação. $\mathrm{Na}$ medida em que os parceiros da auditagem são emparel hados em todas as características mais relevantes para o processo de contratação (escolaridade, experiência, aparência física etc.), os empregadores podem sever forçados a val orizar características relativamente irrelevantes, apenas pela necessidade de tomar uma decisão. "C onsiderando-se os componentes comuns mais freqüentemente medidos, as diferenças nas taxas de contratação monitoradas pelas auditagens originam-se de fatores idiossincráticos e não dos fatores principais que determinam os mercados de trabalho reais" (H eckman, 1998, p. 111). Se os empregadores preocupam-se apenas marginalmente com a raça, mas vêem-se confrontados a dois candidatos equivalentes em todas as demais características, a raça pode assumir uma dimensão maior na decisão de contratar do que seria normal em circunstâncias reais, baseadas na avaliação de candidatos que diferem entre si segundo múltiplas variáveis.

Tal crítica, de novo, é significativa, embora possa ser respondida mais facilmente. Seo único resultado importantede um estudo deauditagem ése um candidato obteve o emprego ou não, então as considerações de H eck-
19. Em vista da amplitude de habilidades requeridas, é comum que os pesquisadores examinem cuidadosamente entre cinqüenta e cem candidatos (já previamenteselecionados com relação à idade, raça ou gênero) antes de encontrar um único par combinável.

20. D eve-se observar igualmente que o mé todo de correspondência não é afetado pelos problemas de emparelhamento, já que a raça pode ser atribuída de modo experimental. As evidências de discriminação produzidas por esses estudos ajudam a confirmar os resultados de estudos de auditagem em pessoa. 
man são relevantes. Forçadosa escolher um único candidato, os empregadoresusarão qual quer elemento de diferenciação disponível, seja ele considerado muito ou pouco relevante. 0 s estudos de auditagem, que medem retorno de chamadas telefônicas como variável resultante, evitam, ao contrário, situações nas quais os em regadores podem escolher apenas um candidato. Empregadores, com efeito, entrevistam em média oito candidatos para cada posto de trabal ho inicial que preenchem. Se raça fosse uma preocupação de pouca importância para os empregadores, seria de esperar que os dois membros de uma dupla de auditagem passassem pela primeira tentativa. $\mathrm{N}$ a medida em que a raça aparece de modo proeminente já nos primeiros estágios do processo, podemos inferir que ela é mais do que simplesmente um último fator na decisão.

U ma terceira e importante crítica à metodologia de auditagem levanta a questão dosviesesintroduzidos pelo experimentador, ou seja, a possibilidade de que as expectativas ou comportamentos dos testadores possam influenciar os resultados da auditagem de um modo não aleatório. Se um testador, por exemplo, esperar ser tratado de modo rude por um empregador, pode mostrar-semenos participativo, maisnervoso ou na defensivaduranteainteração. A própria natureza da interação pode, assim, criar uma profecia autorealizável, na qual o testador obtém resultados pífios, mas por motivos não relacionados com a condição experimental (por exemplo, seu registro policial). $N$ a verdade, a possibilidade devieses produzidospelo experimentador é uma das ameaças mais sérias à validade dostestes de auditagem. Embora não haja maneiras de evitar de modo conclusivo tal possibilidade, há algumas precauções que podem ser tomadas para minimizar o problema. Em primeiro lugar, o treinamento efetivo e a supervisão são fundamentais para uma implementação bem-sucedida de um estudo de auditagem. O s testadores devem estar extremamentefamiliarizadoscom os perfisquedevem assumir e com o protocolo de auditagem, de modo que as respostas apropriadas às questões dos empregadorestornem-sequaseautomáticas. Ensaios prolongados, gravação de entrevistas e auditagens práticas ajudam os testadores a se sentirem confortáveis em seus papéis e obter um retorno importante sobre seu desempenho. D a mesma forma, duranteo trabal ho decampo, relatórios diários e sessões para resolução de problemas são de extrema importância para identificar qualquer questão potencial ou para redefinir o protocolo do modo mais adequado às características do estudo. Além disso, quando o trabal ho de campo acaba, épossível proceder auma verificação indireta dosvieses introduzidos pelo testador. G eralmente, al guns testes são realizados com 
pouco ou nenhum contato pessoal, seja porque o empregador está ausente, seja porque não tem tempo deencontrar o candidato. Comparando-seosresultados de auditagem obtidos por testadores que tiveram ou não contato com empregadores, pode-se determinar o grau em que a interação pessoal leva a uma distribuição diferente dos resultados. C aso os testadores estejam agindo de uma maneira que corresponda às suas expectativas de discriminação, devemos esperar que os testes real izados por meio deinteração mostrem maior evidência de discriminação do que aqueles sem interação. Se os resultados forem semelhantes, ou mostrarem menor evidência de discriminação, podemos ter maior confiança de que o comportamento do experimentador não está alterando os resultados (cf. Bertrand e M ullainathan, 2004; Schwartz eSkolnick, 1962).

Como observação final, vale a pena reiterar que a principal vantagem dos testes por correspondência (em comparação às auditagens em pessoa) é sua capacidade de apresentar pares combinados de currículos para empregadores sem 0 uso de testadores reais. 0 fato de esses estudos também demonstrarem, em geral, evidências consistentes de discriminação é mais um motivo para estarmos seguros de que os resultados dos estudos de auditagem em pessoa não são apenas produto de expectativas atuantes nos e pelos participantes.

\section{Conclusão}

A despeito de sua grande complexidade, o método de auditagem éainda a abordagem mais eficaz para medir a discriminação em contextos reais. Participando de procuras reais por emprego e simulando o procedimento de candidatos reais, obtemos a maior aproximação possível com as interações que produzem discriminação nos mercados de trabal ho contemporâneos. $\mathrm{N}$ enhum método é infalível, mas um exame cuidadoso das possibilidades disponíveis auxilia a encontrar a estratégia empírica apropriada às questões propostas por uma pesquisa. Embora o método de auditagem não possa responder a todos os aspectos importantes da desvantagem no mercado de trabalho, ele oferece medições precisas e diretas da discriminação no momento da contratação, um mecanismo poderoso na regulação das oportunidades de emprego. 


\section{Referências Bibliográficas}

Ayres, Ian \& Siegelm an, Peter. (1995), "Raceand gender discrimination in bargaining for a new car". The American Economic Review, 85 (3): 304-321.

Bendick JR., M arc; Jackson, Charles \& Reinoso, Victor. (1994), "M easuring employment discrimination through controlled experiments". Review of Black Political Economy, 23: 25-48.

Bendick JR., M arc; Brown, Lauren \& W alL, Kennington. (1999), "No foot in the door: an experimental study of employment discrimination". Journal of Aging and Social Policy, 10: 5-23.

Bertrand, M arianne \& M ullain ath an, Sendhil. (2004), "Are Emily and Greg more employable than Lakisha and Jamal? A field experiment on labor market discrimination". The American Economic Review, 94: 991-1013.

Bobo, Lawrence; Kluegel, James \& SM Ith, Ryan. (1997), "Laissez-faire racism: the crystallization of a 'kindler, genter' anti-black ideology". In: TucH, Steven A. \& MARTIN, Jack K. (eds.), Racial attitudes in the 1990s: continuity and change. Westport, CT, Praeger.

Bodenhausen, Galen. (1988), "Stereotypic biases in social decision making and memory: testing process models of stereotype use". Journal of Personality and Social Psychology, 55: 726-737.

Cancio, A. Silvia; Evans, T. David \& M aume, D avid J. (1996), "Reconsidering the declining significance of race: racial differences in early career wages". American Sociological Review, 61 (4): 541-556, ago.

CARR, D eborah \& FRIEDMAN, Michael A. (2005), "Is obesity stigmatizing? Body weight, perceived discrimination, and psychological well-being in the United States". Journal of Health and Social Behavior, 46: 244-259, set.

Corrigan, Patrick et al. (2003), "Perceptions of discrimination among persons with serious mental illness". Psychiatric Services, 54 (8): 1105-1110.

CRoSBY, Faye. (1984), "The denial of personal discrimination". American Behavioral Scientist, 27: 371-386.

C Ross, $\mathrm{H}$ arry et al. (1990), Employer hiring practices: differential treatment of $\mathrm{H}$ ispanic and Anglo job seekers. Washington, D.C., U rban Institute Press.

Farkas, George. (2003), "Cognitive skills and noncognitive traits and behaviors in stratification processes". Annual Review of Sociology, 29: 541-562.

FeAgIN, Joe R. \& Sykes, M elvin P. (1994), Living with racism: the black middleclass experience. Boston, M A, Beacon Press.

Fernandez, Roberto \& Su, Celina. (2004), "Space in the study of labor markets". Annual Review of Sociology, 30: 545-569, ago. 
FIX, M ichael \& StruYk, Raymond J. (eds.). (1993), Clear and convincing evidence measurement of discrimination in America. Washington, D.C., U rban Institute Press.

Fryer J R., Ronald G. \& LeVItT, Steven D. (2004), "T he causes and consequences of distinctively black names". The Q uarterly Journal of Economics, CXIX: 767-805.

Goff, Philip Atiba. (2005), The spacebetween us: stereotypethreat for whitesin interracial domains. D octoral dissertation. Department of Psychology, Stanford University.

H AKKEN, Jon. (1979), Discrimination against Chicanos in the D allas Rental Housing $M$ arket: an experimental extension of the Housing M arket Practices Survey. Washington, D.C., U.S. D epartment of H ousing and Urban D evelopment.

H ECKMAN, James J. (1998), "D etecting discrimination". The Journal of Economic Perspectives, 12(2): 101-116.

Heckman, James \& Siegelman, Peter. (1993), "The urban institute audit studies: their methods and findings". In: FIX, M ichael \& STRUYK, Raymond J. (eds.), Clear and convincing evidence: measurement of discrimination in America. Washington, D.C., Urban Institute Press, pp. 187-258.

Kessler, Ronald C.; Mickelson, Kristin D. \& W Illiams, D avid R. (1990), "The prevalence, distribution, and mental health correlates of perceived discrimination in the United States". Journal of H ealth and Social Behavior, 40 (3): 208-230.

Kinder, Donald R. \& Sears, D avid O (1981), "Prejudice and politics: symbolic racism versus racial threats to the good life". Journal of Personality and Social Psychology, 40: 414-431.

KirSh enm An, Joleen \& N eckerman, Kathryn. (1991), "W e'd love to hire them, but...: the meaning of race for employers". In: Jencks, Christopher \& Peterson, P. E. (eds.), The urban underdass Washington, D.C., Brookings Institution, pp. 203-234.

Kutner, Bernard; Wilkins, Carol \& Yarrow, Penny Rechtman. (1952), "Verbal attitudes and overt behavior involving racial prejudice". Journal of Abnormal Social Psychology, 47: 649-52.

LAHEY, Joanna. (2005), "Age, women, and hiring: an experimental study". NBER, Working Paper 11435.

LaPierre, Richard T. (1934), "Attitudes vs. actions". Social Forces, 13: 230-237.

M arwelL, Gerald \& Ames. Ruth E. (1981), "Economists free ride, does anyone else?". Journal of Public Economics, 15 (3): 295-310.

M ASSEY, Douglas \& LUNDY, Garvey. (2001), "Use of black English and racial discrimination in urban housing markets: new methods and findings". U rban Affairs Review, 36: 452-469.

M cConAhAY, J. B. (1986), "M odern racism, ambivalence, and the modern racism scale". In: D ovidio, J. F. \& Gaertner, S. L. (eds.), Prejudice, discrimination, and racism. San Diego, CA, Academic Press. 
M oss, Philip \& TILly, Chris. (1996), "'Soft sills' and race: an investigation of black men's employment problems". Work and 0 ccupations, 23: 256-276.

National Research Council. (2004), "M easuring racial discrimination". Panel on Methods for Assessing Discrimination. Edited by Rebecca M. Blank, M arilyn Dabady e Constance F. Citro, Committee on National Statistics, Divison of Behavior and Social Sciences and Education. Washington, D.C., The N ational Academies Press.

N eum ARK, D avid. (1996), "Sex discrimination in restaurant hiring: an audit study". Q uarterly Journal of Economics, 111: 915-941.

N ew m AN, Katherine. (1999), No Shame in my game: the working poor in the Inner city. $\mathrm{N}$ ova York, Random $\mathrm{H}$ ouse.

PAGER, D evah \& Q UILLIAN, Lincoln. (2005), "Walking the talk: what employers say versus what they do". American Sociological Review, 70 (3): 355-380.

R $\triangle A C H$, Peter \& RıCH, Judith. (1991), "M easuring discrimination by direct experimentation methods: seeking gunsmoke". Journal of PostKeynesian Economics, 14: 143-150.

. (2002), "Field experiments of discrimination in the market place". The Economic Journal, 112: 480-518.

RidLEY, Stanley; BAYTon, JamesA. \& O uttz, JaniceH amilton. (1989), Taxi servicein the D istrict of Columbia: isit influenced by patrons raceand destination?Washington, D.C., Washington Lawyers' Committee for Civil Rights under the Law, mimeo.

Saen Ger, Gerhart \& Gilbert, Emily. (1950), "Custom reactions to the integration of negro sales personnel". International Journal of O pinion and Attitude Research, 4: $57-76$.

Sagar, H. A. \& Schofield, J. W. (1980), "Racial and behavioral cues in black and white children's perceptions of ambiguously aggressive acts". J ournal of Personality and Social Psychology, 39: 590-598.

Schuman, H. (1995), "Attitudes". In: Cook, Karen; Fine, Gary \& H ouse, James (eds.), Sociological perspectives on social psychology. Boston, Allyn and Bacon.

Schum An, H oward \& BoBo, Lawrence. (1988), "Survey based experiments on white racial attitudes toward residential integration". American Journal of Sociology, 94: 273-299.

Sch u M AN , H oward et al. (2001), Racial attitudesin America: trendsand interpretations. 1a edição 1997. Cambridge, M A, H arvard University Press.

Schwartz, Richard \& Skolnick, Jerome. (1962), "Two studies of legal stigma". Social Problems, 10: 133-142.

Sм ітн, Tom W. (1991), "Ethnic images. General social survey technical report, 19". Chicago, National O pinion Research Center, University of Chicago. 
. (2001), Intergroup relations in a diverse America: data from the 2000 general social survey. N ova York, American Jewish Committee.

Sniderman, Paul M . \& Grob, D ouglas B. (1996), "Innovation in experimental design in attitude surveys". Annual Review of Sociology, 22: 377-399.

TAYLOR, D. M. et al. (1990), "The personal/group discrimination discrepancy: perceiving my group, but not myself, to be a target of discrimination". Personality and Social Psychology Bulletin, 16: 254-262.

Turner, M argery; Fix, M ichael \& Struyk, Raymond. (1991), Opportunities denied, opportunities diminished: racial discrimination in H iring. Washington, D .C., U rban Institute Press.

T URNER, M argery \& SKIDM ORE, Felicity (eds.). (1999), M ortgagelending discrimination: a review of existing evidence. Washington, D.C., The U rban Institute.

W IEN K, Ronald E. et al. (1979), M easuring discrimination in American housing markets: the housing market practi ces survey. Washington, D.C., U .S. D epartment of H ousing and U rban D evelopment.

W ILson, William Julius. (1996), When work disappears: the world of the new urban poor. N ova York, Vintage Books.

Yinger, John. (1995), Closed doors, opportunities lost. N ova York, Russell Sage Foundation.

\section{Resumo}

Medir a discriminação

O s debates a respeito da rel evância contemporânea da discriminação são obscurecidos pela ausência de técnicas rigorosas de mensuração. C omo separar os efeitos gerados pela raça das várias outras fontes de desigual dade social? 0 artigo examina as abordagens normalmente empregadas para medir a discriminação, como estudos de percepção, levantamentos de atitudes, análises estatísticas, experimentos de laboratório e de campo. As várias abordagens são resumidas e o alcance e a limitação de cada uma delas são avaliados. Embora nenhum método de pesquisa seja isento de falhas, a análise cuidadosa dos métodos disponíveis ajuda a estabelecer a correspondência entre o problema da pesquisa e a estratégia empírica adequada.

Palavras-chave: D iscriminação racial; M edidas de discriminação; Estratégias de pesquisa.

\section{Abstract}

Measuring discrimination

D ebates about the contemporary relevance of discrimination have been clouded by a lack of rigorous measurement techniques. $\mathrm{H}$ ow can we disentangle the effects of race 
from the many other sources of social inequality? W hat are the obstacles to developing reliable measures of racial discrimination? This article addresses the state-of-theart approaches to measuring discrimination, including studies of perceptions, attitude surveys, statistical analyses, laboratory and field experiments, and provides a brief overview of the varying approaches, examining their unique strengths and limitations. While no research method is without flaws, careful consideration of the range of methods available helps to match one's research question with the appropriate empirical strategy.

Keywords: Racial discrimination; M ethods of measurement; Audits.

D evah Pager é professora do Departamento de Sociologia da Universidade de Princeton.E-mail: pager@ princeton.edu. 